\title{
Ca isotope composition of the altered oceanic crust from the IODP Site 1256 at the East Pacific Rise
}

\author{
LINGZHI HU ${ }^{1}$, YUHAN QI ${ }^{1,2}$, JINTING KANG ${ }^{1}$ AND \\ FANG HUANG ${ }^{3}$ \\ ${ }^{1}$ University of Science and Technology of China \\ ${ }^{2}$ University of Alberta \\ ${ }^{3}$ CAS Key Laboratory of Crust-Mantle Materials and \\ Environments, School of Earth and Space Sciences, University \\ of Science and Technology of China \\ Presenting Author: harryhu@mail.ustc.edu.cn
}

In order to constrain the $\mathrm{Ca}$ isotope composition of the altered oceanic crust (AOC) and better understand the behavior of $\mathrm{Ca}$ isotopes in the oceanic crust during seawater alteration, we analyzed $\mathrm{Ca}$ isotope for twenty-one samples from the IODP1256 site. This drill profile has four sections from top to bottom, including the volcanic section, transition zone, sheeted dyke complex, and plutonic complex. The volcanic section is slight to moderately altered by seawater at 100 to $250^{\circ} \mathrm{C}$ from top to bottom, including the volcanic section, the hydrothermal fluids and downwelling seawater; and the sheeted dyke complex and plutonic complex are highly altered by hydrothermal fluids $\left(>250^{\circ} \mathrm{C}\right)$.

Calcium isotopes were analyzed on a Neptune Plus MC-ICPMS at the Arizona State University. The samples have $\delta^{44 / 40} \mathrm{Ca}$ from $0.79 \%$ to $1.02 \%$ (relative to SRM915a) with an average value $(0.86 \pm 0.14 \%$ ) similar to fresh mid-ocean ridge basalt (MORB). No correlations are found between $\delta^{44 / 40} \mathrm{Ca}$ and alteration indicators such as $\delta^{18} \mathrm{O}$ and LOI, suggesting that the hydrothermal alteration cause minor $\mathrm{Ca}$ isotope fractionation in AOC. However, such a signature contradicts the fact that secondary minerals precipitation (e.g., anhydrite and epidote) could fractionate the $\mathrm{Ca}$ isotope composition of hydrothermal fluids towards a higher value ${ }^{[1,2]}$. This may reflect the low water/rock ratios or porosity within the fracture in AOC at IODP-1256 site.

[1] Amini et al. (2008) GCA 72, 4107-4122;

[2] Brown et al. (2020) EPSL 535, 116101. 